\title{
Contribuições da Geometria Dinâmica na Introdução ao Estudo de Perspectiva para Alunos do Ensino Médio
}

\section{Dynamic Geometry Contribution in the Introduction to the Perspective Study for High School Students}

\author{
Maria Elisa Esteves Lopes Galvão* \\ ORCID iD 0000-0003-3899-711X \\ Vera Helena Giusti de Souza** \\ ORCID iD 0000-0003-0705-0839 \\ Lucas Cunha Bastos ${ }^{* * *}$ \\ ORCID iD 0000-0002-7815-2018
}

\begin{abstract}
Resumo
Neste artigo, teve-se por objetivo investigar as contribuições de uma proposta interventiva de ensino de Geometria, baseada nas ideias básicas da perspectiva, para ampliar o repertório de representações planas e as habilidades de visualização de dez alunos do Ensino Médio de uma escola pública brasileira do Ceará. Com base no desenvolvimento histórico de técnicas para a representação plana de figuras espaciais e orientados metodologicamente pelo Design Experiment, elaboraram-se atividades para, em três encontros, analisar pinturas e imagens de várias épocas e utilizar um ambiente de Geometria Dinâmica para explorar técnicas de construção de imagens em perspectiva. Procurou-se suporte teórico nos estudos de Parzysz e de Gutiérrez sobre representações planas de figuras espaciais, particularmente nas ideias de polo do "visto" e polo do "sabido". A análise qualitativa dos dados evidenciou que o uso de um software pode despertar interesse por construções geométricas e por Geometria e mostrou que houve limitações no aprendizado de novos conceitos relativos às representações, principalmente os baseados nos previamente estabelecidos desses participantes. Por outro lado, o uso do software permitiu que alguns participantes se conscientizassem da importância do conhecimento das regras de representação para a interpretação de imagens em perspectiva, o que mostra que um trabalho dessa natureza, a longo prazo, pode promover aprendizagem e visualização em Geometria.
\end{abstract}

Palavras-chave: Perspectiva. Geometria Dinâmica. Visualização.

\begin{abstract}
The objective was to investigate contributions of an interventional proposal using perspective initial ideas for Geometry teaching, in order to expand the repertoire of plane representations and spatial visualization abilities

\footnotetext{
* Doutor em Matemática, USP. Professor Doutor, USP, UNIAN, São Paulo, SP, Brasil. Rua Carajuá, 60, Apto. 12, Moema, 04520-020, São Paulo, SP, Brasil. elisa.gal.meg@ gmail.com.

** Doutor em Educação Matemática, PUC-SP. Professor Doutor Sênior, USP, São Paulo, SP, Brasil. Rua José Alves Cunha Lima, 159, Apto. 1053, Vila Butantã, 05360-050, São Paulo, SP, Brasil.verahgsouza@gmail.com.

${ }^{* * *}$ Mestre em Educação Matemática, UNIAN. Professor da Rede Estadual, Fortaleza, CE, Brasil. Rua Juvenal de Carvalho 1051, Apto. 202C, Fátima, 60050-220, Fortaleza, CE, Brasil, lucascbastos@gmail.com.
} 
for ten Brazilian High School students. Based on the historical development of techniques for bidimensional representations of spatial figures and methodologically oriented by Design Experiment procedures, activities have been developed in three meetings, at first to analyze paintings and images from various times and, afterwards, using the Dynamic Geometry environment to explore techniques for constructing images in perspective. We sought theoretical support in Parzysz and Gutiérrez's studies on bidimensional representations of spatial figures, particularly on the ideas of "seeing" and "knowing" poles. Qualitative data analysis showed that using a software may provoke interest on geometric constructions and Geometry study, although there were limitations in learning new concepts, especially those based on those participants previous ones. On the other hand, using the software has allowed some participants to become aware of the importance of knowing the representation rules for the interpretation of images in perspective, which shows that a long-term work of this nature can promote learning and visualization in Geometry.

Keywords: Perspective. Dynamic Geometry. Visualization.

\section{Introdução}

Tivemos por objetivo organizar um conjunto de atividades que possibilitassem uma iniciação à geometria projetiva, por meio de ideias iniciais da perspectiva e investigar as contribuições dessa proposta interventiva para ampliar o repertório de representações planas e a visualização de dez alunos do Ensino Médio de uma escola pública. Como as imagens em perspectiva podem ser identificadas com representações planas de figuras tridimensionais, consideramos que conhecer aspectos e princípios adotados nessas representações pode colaborar para o desenvolvimento de habilidades de visualização, como indicam os Parâmetros Curriculares Nacionais do Ensino Médio (BRASIL, 2015) e a Base Nacional Comum Curricular (BRASIL, 2017).

[...] as habilidades de visualização, desenho, argumentação lógica e de aplicação na busca de soluções para problemas podem ser desenvolvidas com um trabalho adequado de Geometria, para que o aluno possa usar as formas e propriedades geométricas na representação e visualização de partes do mundo que o cerca (BRASIL, 2015, p. 44).

O desenvolvimento da habilidade de desenhar objetos em perspectiva é iniciado no $9^{\circ}$ ano, a partir do reconhecimento e da representação intuitiva de vistas ortogonais. Não se trata de ensinar técnicas do desenho em perspectiva, mas da proposição de atividades que envolvem a construção com auxílio de instrumentos de desenho para construir esboços de representações de figuras espaciais no plano, aprimorando ainda mais a sua percepção visual (BRASIL, 2017, p. 405).

[...] Estabelecer relações entre vistas ortogonais e representações em perspectiva de figuras geométricas espaciais e de objetos do mundo físico e aplicar esse conhecimento em situações relacionadas ao mundo do trabalho (BRASIL, 2017, p. $565)$.

Em cinco coleções de livros didáticos de Matemática do Ensino Fundamental, anteriores à BNCC e aprovadas pelo Programa Nacional do Livro Didático de 2014 só encontramos referência à perspectiva no livro do nono ano de uma delas. No capítulo "Como aprender a desenhar em 3D”, os autores Imenes e Lellis (2014) colocam uma análise de pinturas que destacam a noção de profundidade e uma explicação sobre como construir um 
quadrado ou um retângulo com a perspectiva cônica, com base nos conceitos de ponto de fuga e linha do horizonte.

Considerando pertinentes as recomendações e a ausência de material didático para modernizar o ensino de Geometria, propusemo-nos a investigar se aspectos relacionados à perspectiva contribuem para desenvolver habilidades de visualização. Trazemos alguns dos resultados obtidos nesse estudo, realizado com dois objetivos: introduzir a geometria projetiva com o uso de um software, por meio de ideias iniciais da perspectiva; e apresentar algumas propriedades de um modelo de geometria não euclidiana.

\section{Considerações gerais sobre a pesquisa}

As ideias introdutórias sobre técnicas de representação plana de figuras espaciais que usamos baseiam-se nas referências de caráter histórico do trabalho de Alberti (1991). Também foram relevantes os trabalhos de Souza (2010), Miranda (2006), Kodama (2006) e Meneguzzi (2009), dentre outros.

Encontramos no trabalho de Souza (2010) uma investigação sobre o uso de imagens variadas para o desenvolvimento de habilidades de visualização. Miranda (2006) teve por objetivo investigar quais secções planas de um cubo podem ser visualizadas com o uso de Geometria Descritiva, com suporte num software de geometria dinâmica e identificar relações entre uma figura e representações dela na Geometria Espacial e na Geometria Descritiva. Kodama (2006) estudou a perspectiva cavaleira. Meneguzzi (2009) explorou uma sequência histórica, que nos leva a Dürer ${ }^{1}$, o criador das máquinas de perspectiva - os perspectógrafos para trabalhar conceitos geométricos espaciais, aliando a história da perspectiva a conhecimentos empregados em técnicas de desenho.

Orientamos a intervenção pelo Design Experiment (COBB et al., 2003), por sua natureza avaliativa e reflexiva e por entender que a compreensão é parte essencial de nossos objetivos. Avaliar o que se ensina e, em seguida, retomar o que foi ensinado, com base nos resultados obtidos e assim por diante, como sugerem Cobb et al. (2003), favorece essa compreensão.

Buscamos responder três questões: "O aluno percebe a importância e a necessidade das técnicas de representação da perspectiva, a partir da análise de obras de arte?”; “A

\footnotetext{
${ }^{1}$ http://www.uh.edu/engines/epi138.htm
} 
utilização de um software de Geometria Dinâmica para trabalhar com projeções de figuras facilita o entendimento dessas técnicas?"; "O estudo de uma geometria não-euclidiana desperta o interesse pelo estudo de Geometria?"

Para a coleta de dados, elaboramos um conjunto de atividades que foram realizadas em três encontros, com 10 alunos do $2^{\circ}$ ano do Ensino Médio da rede pública estadual do Ceará.

No primeiro encontro, apresentamos os principais aspectos históricos da evolução das técnicas de perspectiva e os conceitos geométricos que embasam essas técnicas, como paralelismo, pontos médios e diagonais. Em seguida, os participantes observaram obras de arte de diferentes períodos e responderam questões relacionadas à representação plana de figuras tridimensionais.

No segundo encontro, introduzimos as noções de "ponto de fuga" e de "linha do horizonte", ferramentas usadas por artistas para ressaltar pontos específicos de suas pinturas e como estão relacionadas ao paralelismo, na perspectiva. Construímos um paralelogramo em perspectiva e os participantes usaram papel, lápis e régua para construir a projeção em perspectiva de uma série de exemplos propostos por nós.

No terceiro e último encontro, discutimos exemplos que destacam a evolução histórica de estratégias básicas de construção, reproduzidas num ambiente de Geometria Dinâmica. Os participantes responderam algumas questões sobre a influência do uso do recurso computacional na compreensão dos conceitos introduzidos pelos modelos apresentados.

A análise qualitativa dos dados foi conduzida à luz dos estudos de Parzysz (1998) e Gutiérrez (1998) sobre representações planas de figuras espaciais. Parzysz (1998) investiga a perda de informação nas representações e traça um paralelo entre o conhecimento e a percepção, com o conflito entre o polo do visto e o polo do sabido. O polo do visto refere-se à interpretação dos elementos presentes na representação bidimensional de um ambiente ou objeto; o polo do sabido refere-se ao que se conhece de um objeto ou ambiente, não vinculado ao que está representado, mas sim às suas características e propriedades.

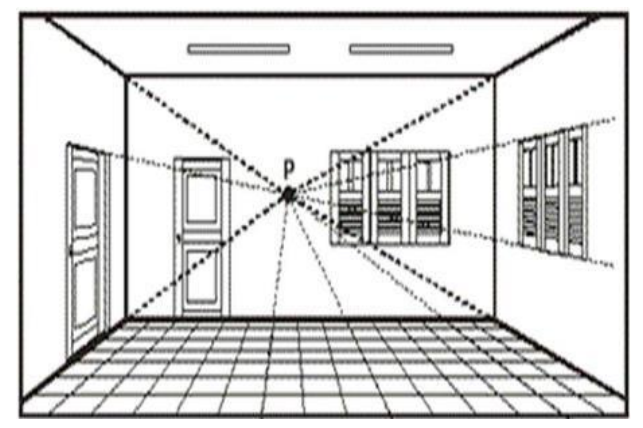

Figura 1 - Ponto de fuga de imagem em perspectiva Fonte: LELLIS (2009) 
Por exemplo, na Figura 1 (LELLIS, 2009), "vemos” que as retas que representam o solo não são paralelas - polo do visto - se nos limitarmos ao que a imagem nos revela, mas "sabemos" que representam retas paralelas - polo do sabido - se a interpretarmos pelas propriedades que conhecemos do ambiente e não apenas pelo que se vê na representação.

Gutierrez (1998) propõe um conjunto de habilidades para fazer ou interpretar representações planas de figuras espaciais e, como Parzysz (1998), considera que essas representações trazem dificuldades, que resume em duas: 1. Interpretar a representação plana para compreender a figura tridimensional original, o que Parzysz (1998) chama decodificar a representação; 2. Compreender o objeto tridimensional para construir a representação plana, ou seja, codificar a figura, segundo Parzysz (1998).

Entendemos que o uso de um software de geometria dinâmica pode auxiliar o entendimento da perspectiva e das diferenças e semelhanças entre ambientes reais e outros, como o do computador. Nossas atividades buscaram mostrar como funcionam "na prática" representações planas de ambientes e objetos tridimensionais, com o objetivo de gerar um conhecimento que sirva para a compreensão de situações da vida real.

\section{As primeiras técnicas de perspectiva}

As primeiras técnicas de perspectiva surgiram na Itália no século $\mathrm{XV}$, mas, no século XIII, alguns artistas, como Giotto e Lorenzetti, buscavam criar imagens mais fidedignas à realidade, por meio de cores e do posicionamento dos elementos na representação da imagem. Em pinturas como "Adoração dos Magos" (Figura 2) e "Cenas da vida de São Nicolau" (Figura 3), esses artistas tentam dar uma noção de profundidade pelo uso de retas inclinadas em relação à base da tela, como na perspectiva paralela. Apesar de efetiva para a noção de profundidade, essa técnica não retrata com exatidão a percepção dos elementos pelo olho humano. Brunelleschi (1377-1446), por volta de 1420, foi o primeiro a utilizar princípios de Geometria e disseminar técnicas para estabelecer as ideias iniciais da perspectiva, tais como a proporcionalidade das distâncias e do tamanho dos objetos representados. 


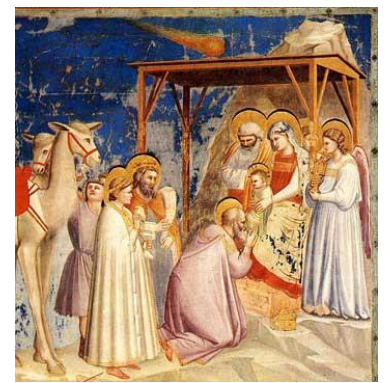

Figura 2- Adoração dos Magos, Giotto, 1305

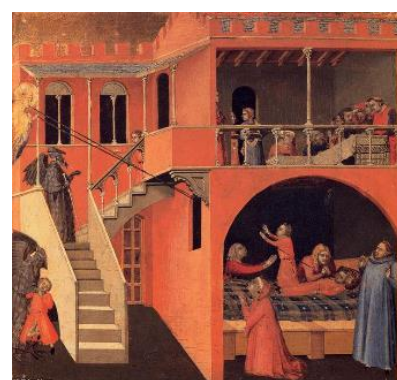

Figura 3 - Cenas da vida de São Nicolau, Lorenzetti, 1332 Fonte: http://pt.wahooart.com. 2018.

Sem um conhecimento sistematizado de geometria para a representação em perspectiva, uma das técnicas usadas pelo artista alemão Albrecht Dürer $^{2}$ (1471-1528) foi colocar uma tela transparente em frente à cena a ser pintada e um suporte que mantinha a cabeça do pintor sempre na mesma posição (Figura 4).

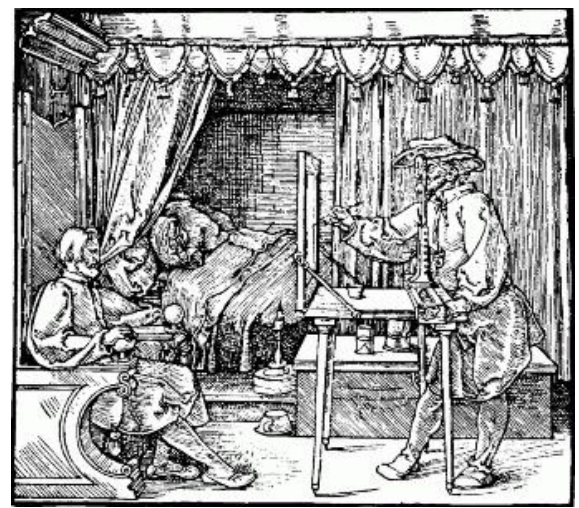

Figura 4 - Albrecht Dürer

Fonte: http://venetianred.net/2010/03/06/hans-holbein-tricks-of-the-trade/. Acesso em: 3 fev. 2018.

As representações feitas com o auxílio do software, como na Figura 5, assemelham-se às de Dürer: a partir de um ponto fixo - o "observador" - traçam-se retas para os pontos da figura a ser representada e marcam-se os pontos de intersecção dessas retas com o plano vertical de projeção, formando a representação plana da figura tridimensional. O polígono de segmentos vermelhos representa apenas as partes que o observador vê, por isso mostra apenas três das seis faces do cubo. 


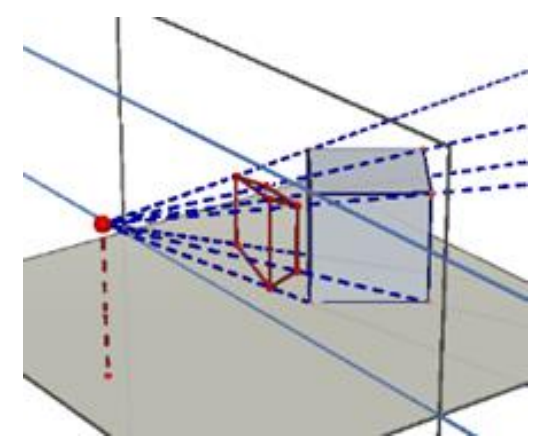

Figura 5 - Representação Plana de uma figura no Software Fonte: Acervo Pessoal (2015)

As primeiras regras para a representação plana de figuras tridimensionais foram descritas por Leon Battista Alberti (1404-1472) em sua obra De Pictura, em latim, publicada em italiano como Della Pintura e em inglês como On Painting (ALBERTI, 1991). Essa obra disseminou as regras da perspectiva nas pinturas, tendo um profundo e imediato retorno dos artistas da época. Alberti dedica o livro a Filippo Brunelleschi (1377-1446), a quem atribui as técnicas para a criação de imagens em telas, segundo uma perspectiva real e semelhante à maneira como o olho humano percebe as paisagens ou objetos. Alberti (1991) traz uma explicação simples e direta dessas técnicas, dividindo-as em quatro etapas, que descrevem os recursos usados à época e seguimos esses passos para a representação de um piso quadriculado.

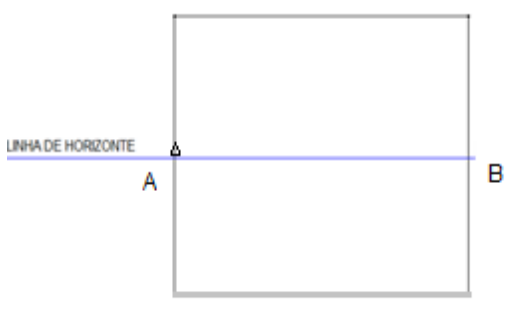

Figura 6 - Construção de Alberti (1)

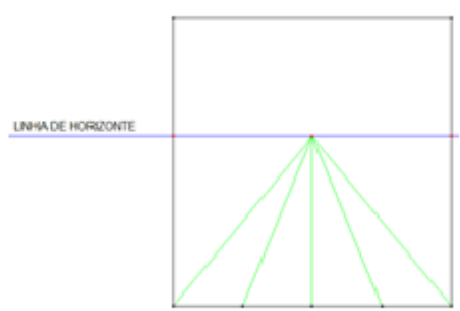

Figura 7 - Construção de Alberti (2)

Fonte: Acervo pessoal (2015)

Na primeira etapa (Figura 6), fixa-se a "linha de horizonte", que corresponde à altura do observador em relação à figura a ser representada e determina-se o segmento intersecção dessa linha com a figura - no caso AB.

$\mathrm{Na}$ segunda etapa (Figura 7), a linha de terra, que é a base da figura, é dividida no número de partes que corresponde à quantidade de peças do piso - no caso, quatro - e é escolhido o ponto médio do segmento $\overline{A B}$ da linha de horizonte como "ponto de fuga" das retas paralelas que são perpendiculares ao plano da figura. São traçados os segmentos que unem os pontos da base da figura ao "ponto de fuga" (ALBERTI, 1991, p. 55). 


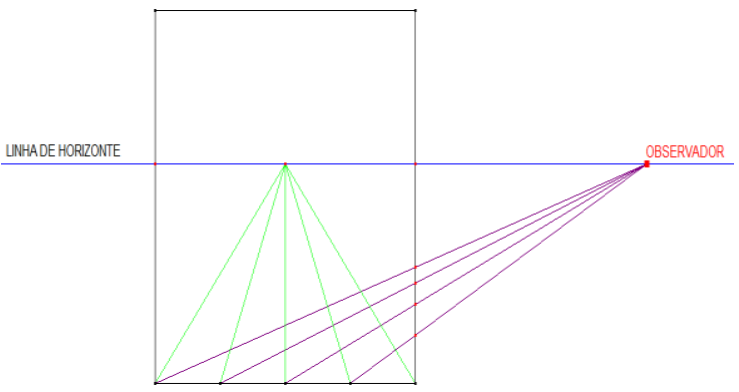

Figura 8 - Construção de Alberti (3)

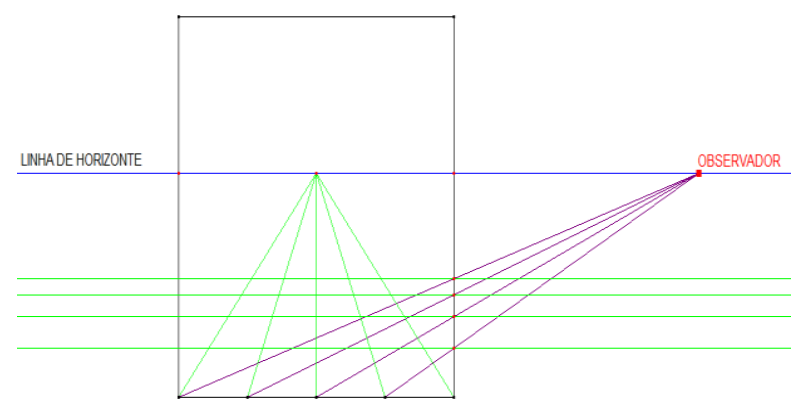

Figura 9 - Construção de Alberti (4)

Fonte: Acervo pessoal (2015)

Na terceira etapa (Figura 8), escolhe-se a posição do observador na linha de horizonte, "ponto de fuga" das retas da figura que são paralelas à linha de terra e traçam-se segmentos de reta entre o observador e os pontos da base da figura, na linha de terra. As intersecções desses segmentos com a linha lateral da tela de pintura servem para o traçado das retas paralelas ao plano da figura e que dão a noção de profundidade das peças do piso na imagem.

$\mathrm{Na}$ quarta etapa (Figura 9), traçam-se as retas paralelas à linha de terra, definindo o piso da imagem. Com esta técnica, Alberti (1991) conseguiu mostrar aos pintores da época como criar a imagem de um piso em perspectiva e com pontos de fuga. Utilizamos os passos de Alberti para orientar a introdução às técnicas de perspectiva em nossas atividades.

\section{Análise dos dados}

No primeiro encontro, a apresentação de aspectos históricos relacionados à perspectiva foi feita a partir de um conjunto de cinco obras de arte de diferentes épocas. Em algumas não são utilizados recursos eficientes para dar a noção de profundidade e, em outras, há uma organização mais sistemática para representar situações compatíveis com a realidade. Mostramos também aspectos instrumentais que acompanharam as mudanças, como aparelhos utilizados desde o século XIII para retratar com maior fidelidade as representações nas pinturas.

Ao final da apresentação histórica, os participantes responderam algumas perguntas sobre a cena representada, tais como o posicionamento, o tamanho e a proporcionalidade dos elementos representados e quais desses elementos deixam clara a noção de profundidade.

Nosso objetivo era diagnosticar a percepção dos participantes quanto à noção de profundidade e ao posicionamento dos elementos, para traçar um paralelo entre o que se vê e o que se sabe e, assim, verificar se os polos do "visto" e do "sabido" estavam em harmonia. 
Buscamos também observar se estabeleceram a relação figura-percepção, pela percepção de relações espaciais e de posicionamento, como proposto por Gutiérrez (1998). Poucos souberam usar os elementos das imagens para perceber a noção de profundidade e constatamos que esta percepção é mais fácil se a imagem é construída com base na perspectiva cônica. Em geral, a atenção dos participantes voltou-se aos aspectos da cena representada e não aos relativos às estratégias ou qualidade da representação.

Ao final do encontro, mostramos como Lellis (2009) utilizou os elementos da figura retas do piso, arestas das janelas e das portas - que são paralelas no real, para observar que convergem para o ponto $(P)$, que é o ponto de fuga principal e por $P$ traçamos uma reta paralela à base da tela de pintura, para representar a linha de horizonte (LH) (ver Figura 1).

Mostramos também como construir a projeção de um paralelogramo, em duas situações: I. os dois pares de lados opostos não são paralelos à linha de terra (Figura 12); II. um dos pares é paralelo à linha de terra (Figura 13).

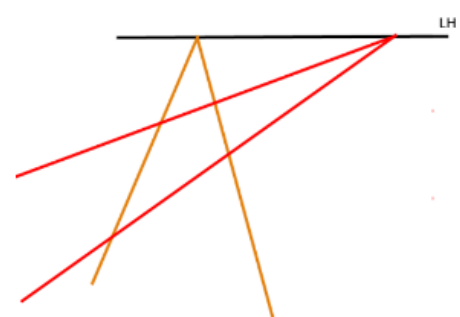

Figura 10 - Traçando um paralelogramo I

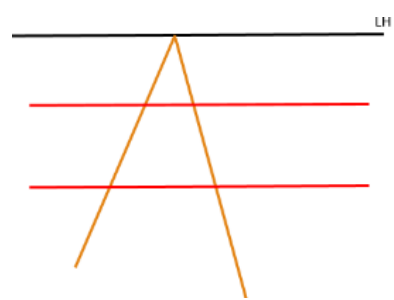

Figura 11 - Traçando um paralelogramo II Fonte: Acervo pessoal (2015)

Na Figura 10, como nenhum dos lados do paralelogramo é paralelo à linha de terra, traçamos as retas amarelas, que correspondem a um par de lados paralelos e, com um outro ponto de fuga, traçamos as retas vermelhas, que correspondem ao outro par de lados paralelos.

Na Figura 11, um par de lados do paralelogramo é representado por retas vermelhas, paralelas à linha de terra e, portanto, à linha de horizonte e a representação do outro par (retas amarelas) é feita a partir de um ponto de fuga qualquer.

Discutimos como encontrar, na representação, o ponto correspondente ao ponto médio de um dos lados do paralelogramo (Figura 12), no caso em que este não tem lados paralelos à linha de terra; lembramos que a reta que passa pelos pontos médios de lados opostos de um paralelogramo é paralela aos outros dois lados e passa pelo ponto de encontro das diagonais, que se interceptam nos pontos médios. Traçamos as diagonais e, a partir de um dos pontos de fuga, a reta que passa pelo encontro das diagonais. Esta reta intercepta o paralelogramo nos pontos médios de dois de seus lados $\left(M^{\prime}\right)$. 


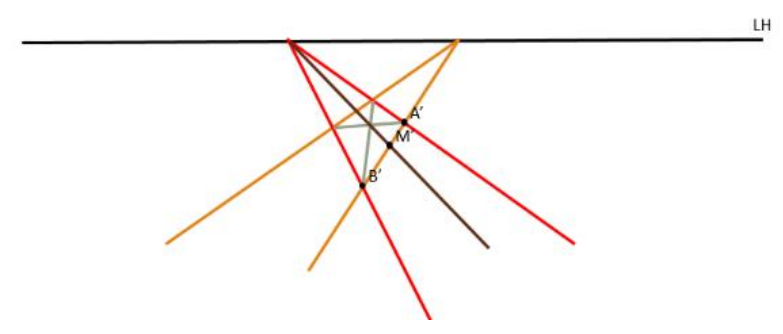

Figura 12 - Marcação de um ponto médio Fonte: Acervo pessoal (2015)

Durante as discussões, os participantes realizaram algumas construções com lápis e régua, para verificar se conseguiam reproduzir as técnicas apresentadas e, ao final do primeiro encontro, identificaram, na projeção de um paralelogramo no plano vertical, o "ponto de fuga", a "linha do horizonte" e localizaram o ponto médio entre dois pontos.

No segundo encontro, propusemos cinco atividades para trabalharem com essas técnicas.

\subsection{Atividade 1}

Um paralelogramo ABCD está situado no plano horizontal. Construir sua perspectiva no plano vertical, que corresponde à folha de papel, e nomear respectivamente de A', B', C'e $D$ 'as perspectivas dos pontos A, B, C e D. É dada a linha do horizonte (LH).

Buscamos avaliar se as técnicas de traçado de paralelas e de paralelogramos eram suficientes para que os participantes as reproduzissem e resolvessem o problema proposto, com base em uma das hipóteses de Parzysz (1988), de que o conhecimento das técnicas e métodos é de fundamental importância para o aprendizado das representações de figuras. Confirmando esta hipótese, todos conseguiram reproduzir as construções dos paralelogramos e alguns deles fizeram os dois tipos vistos durante a discussão.

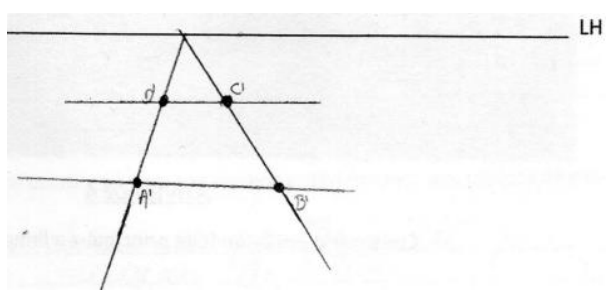

Figura 13 - Resposta do participante A10 à Atividade 1 Fonte: Acervo pessoal (2015)

Notamos que as técnicas mais simples são facilmente assimiladas e reproduzidas, permitindo variações, sem perda de informação, como visto na Figura 13. Nas atividades 1 a 3, buscamos verificar também o nível de interferência que as dificuldades conceituais e 
técnicas descritas por Gutiérrez (1998) tiveram nas construções não usuais, como vemos a seguir.

\subsection{Atividade 2}

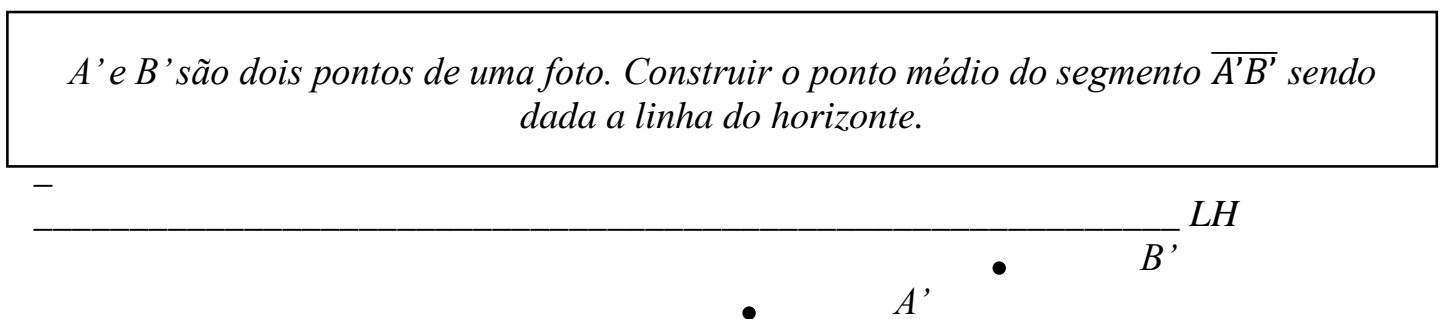

Observamos se os participantes determinaram o ponto médio de $\overline{A^{\prime} B^{\prime}}$ com base na técnica da geometria projetiva apresentada no $1^{\circ}$ encontro. Alguns haviam esquecido os passos da construção e apenas construíram o paralelogramo de lado $\overline{A^{\prime} B^{\prime}}$. O Quadro 1 resume a análise feita com a Atividade 2. As respostas de A3 (Figura 14) e de A10 (Figura 15) trazem, respectivamente, uma construção que segue os procedimentos apresentados por nós, com um acréscimo ao polo do "sabido" e uma que se apoia no polo do "visto", ao marcar o ponto médio de $\overline{A^{\prime} B^{\prime}}$.

\begin{tabular}{|l|l|c|}
\hline Classificamos por & Se a resposta apresentou solução com o uso & $\mathrm{N}^{\circ}$ de alunos \\
\hline Representação Completa & do ponto médio das diagonais do paralelogramo & 4 \\
\hline Representação Incompleta & do ponto médio da geometria plana & 6 \\
\hline Representação Incorreta & incorreto da técnica em questão & 0 \\
\hline Sem resposta & de uma técnica diferente ou sem resposta & 0 \\
\hline
\end{tabular}

Quadro 1 - Categorias de Análise e classificação dos participantes - Atividade 2

Fonte: Acervo pessoal (1995)

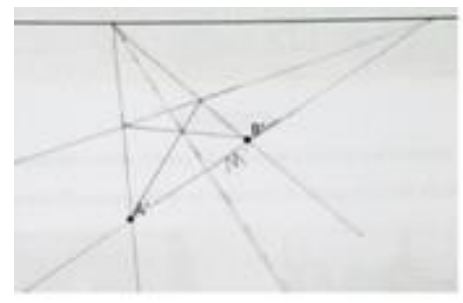

Figura 14 - Resposta de A3 à Atividade 2 Figura 15- Resposta de A10 à Atividade 2 Fonte: Acervo pessoal (1995)

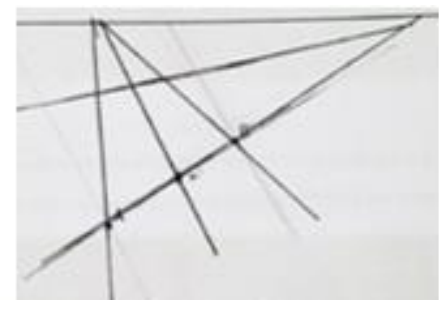

(1)

\subsection{Atividade 3}


As árvores da foto ao lado são equidistantes. Construir a árvore que falta entre 3 e 5.

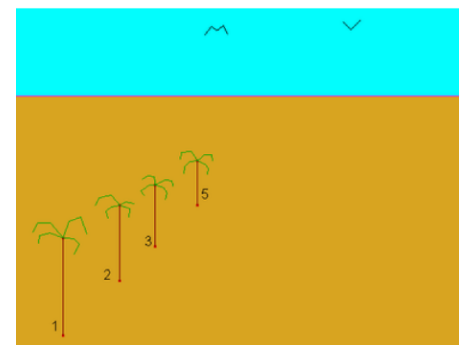

$\mathrm{Na}$ imagem, as árvores são pontos fixos e a linha de horizonte é a reta que divide o céu do deserto, na qual se deve marcar o ponto de fuga de retas paralelas. Esta questão pode ser resolvida com a mesma técnica da questão 2 e a propusemos para verificar se o participante, sem nossa intervenção, usa o conhecimento anterior para responder, pois tiveram que pensar como usariam uma das técnicas vistas, a partir do que já conheciam sobre pontos médios e análise de padrões. O Quadro 2 resume as categorias de análise e a classificação dos participantes da Atividade 3, com base no que foi observado.

\begin{tabular}{|c|c|c|}
\hline Classificamos por & Se a resposta apresentou solução com o uso & $\mathrm{N}^{\mathrm{o}}$ de alunos \\
\hline Representação Completa & correta de um paralelogramo e suas diagonais & 4 \\
\hline Representação Incompleta & $\begin{array}{l}\text { do ponto médio da geometria plana ou parcialmente } \\
\text { correto de um paralelogramo }\end{array}$ & 5 \\
\hline Representação Incorreta & incorreto do paralelogramo e do ponto médio & 1 \\
\hline Sem resposta & de técnica diferente ou sem resposta & 0 \\
\hline
\end{tabular}

Quadro 2 - Categorias de análise e classificação dos participantes - Atividade 3

Fonte: Acervo pessoal (2015).

O enunciado causou dificuldade adicional, pois além de não pedir o uso da técnica diretamente, a Linha de Horizonte fica implícita. Como na Atividade 2, ficou evidente a dificuldade de transitar entre a "figura" e o "desenho", pois alguns nem conseguiram decodificar o enunciado, nem completar o desenho com a técnica vista. As respostas de A7 (Figura 16) e de A1 (Figura 17) mostram a diferença entre entender o uso de uma técnica e entendê-la parcialmente, com falha na execução da mesma. 


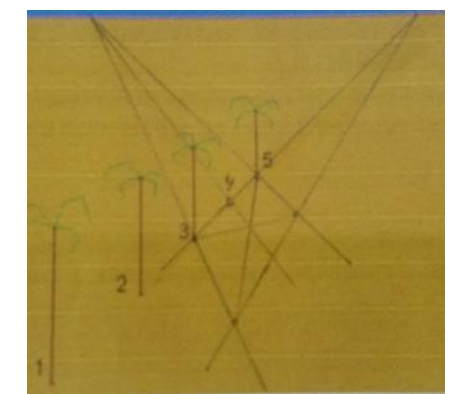

Figura 16 - Resposta de A7 à Atividade 3

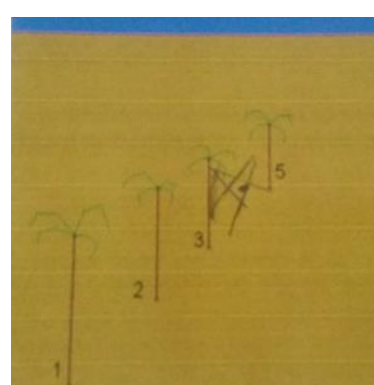

Figura 17 - Resposta de A1 à Atividade 3 Fonte: Acervo pessoal (2015).

Nosso objetivo com as atividades 4 e 5 foi verificar se os participantes conseguem identificar quais elementos da figura representada são paralelos na situação real e como usar esse paralelismo para determinar o ponto de fuga e a linha de horizonte. Analisamos se o participante, a partir da interpretação visual da informação, usa as habilidades de constância perceptiva e de codificação/decodificação, com as quais, segundo Gutiérrez (1988), é possível usar partes da imagem para estabelecer uma relação com o conceito de paralelismo na perspectiva.

\subsection{Atividade 4}

Construir o ponto de fuga principal e a linha de horizonte da Figura 18.

O Quadro 3 traz o resumo da análise feita com a Atividade 4.

\begin{tabular}{|l|l|c|}
\hline Classificamos por & Se a resposta apresentou solução com o uso & $\mathrm{N}^{0}$ de alunos \\
\hline $\begin{array}{l}\text { Representação } \\
\text { Completa }\end{array}$ & $\begin{array}{l}\text { correto de elementos da imagem que representam } \\
\text { paralelismo no real para identificação do ponto de fuga }\end{array}$ & 3 \\
\hline $\begin{array}{l}\text { Representação } \\
\text { Incompleta }\end{array}$ & $\begin{array}{l}\text { parcialmente correto desses elementos associados ao } \\
\text { paralelismo }\end{array}$ & 3 \\
\hline Representação Incorreta & de elementos que não representam paralelismo no real & 3 \\
\hline Sem resposta & de uma técnica diferente ou sem resposta & 1 \\
\hline
\end{tabular}

Quadro 3 - Categorias de Análise e classificação dos participantes - Atividade 4

Fonte: Acervo Pessoal (2015).

Todos tiveram dificuldade para escolher os segmentos que são paralelos, mas quase todos sabiam como encontrar o ponto de fuga. Concluímos que a análise e a decodificação de uma imagem, com elementos geométricos, é uma barreira na resolução de questões, pois foi grande a dificuldade dos participantes para analisar as representações como um modelo de projeção de perspectiva. Alguns entenderam como projeção paralela, que é um modelo mais comum no dia a dia escolar, fazendo com que as construções feitas não atingissem o objetivo 
esperado. O protocolo do participante A3 mostra que ele teve pleno êxito na construção, com o uso dos elementos da imagem para determinar o que se pedia.

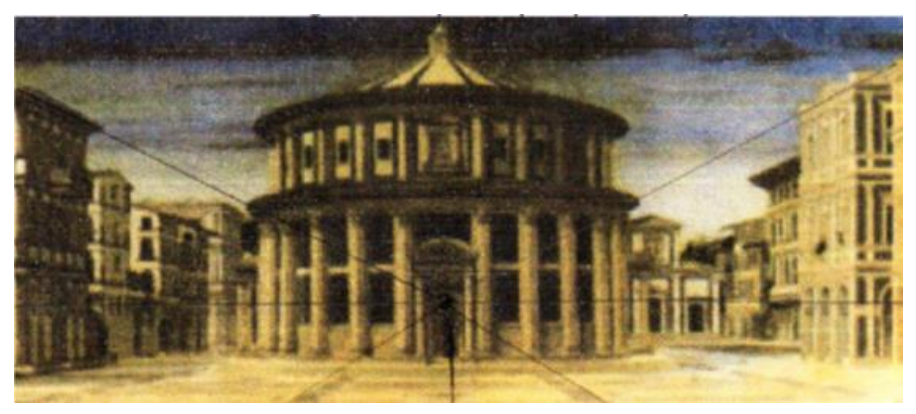

Figura 18 - Resposta de A3 à Atividade 4 Fonte: Acervo pessoal (2015).

\subsection{Atividade 5}

Construir o ponto de fuga principal e a linha do horizonte do quadro "Anunciação", de Leonardo da Vinci em 1473/75, atualmente no Museu do Ofício em Florença (ver Figura 19)

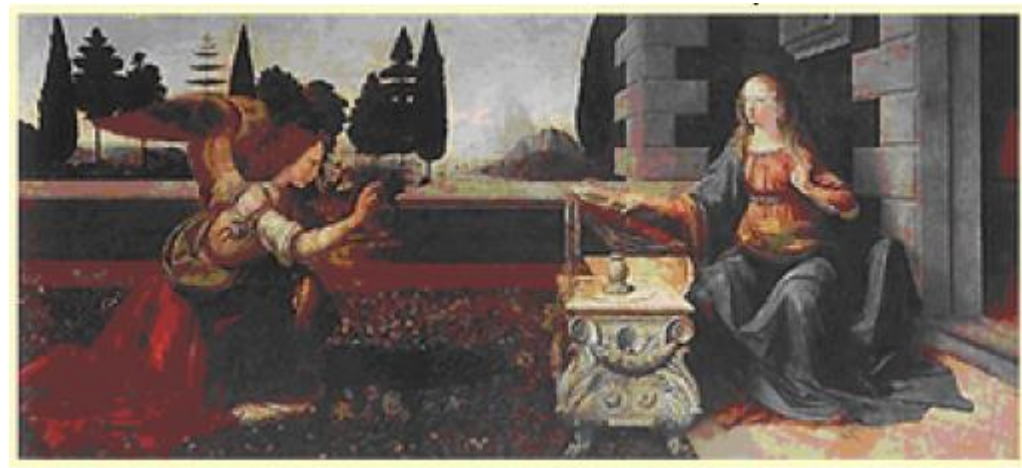

Figura 19 - Anunciação, de Leonardo da Vinci

Fonte: https://pt.wikipedia.org/wiki/A_Anuncia\%C3\%A7\%C3\%A3o_(Leonardo_da_Vinci). Acesso em: 3 fev. 2018.

O Quadro 4 resume as categorias de análise e a classificação dos participantes da Atividade 5, com base no que foi observado.

\begin{tabular}{|c|c|c|}
\hline Classificamos por & Se a resposta apresentou solução com o uso & $\mathrm{N}^{\circ}$ de alunos \\
\hline Representação Completa & $\begin{array}{l}\text { correto de elementos da imagem que representam } \\
\text { paralelismo no real }\end{array}$ & 0 \\
\hline Representação Incompleta & parcialmente correto desse paralelismo & 6 \\
\hline Representação Incorreta & de elementos que não representam paralelismo no real & 0 \\
\hline Sem resposta & de uma técnica diferente ou sem resposta & 4 \\
\hline
\end{tabular}

Quadro 4 - Categorias de Análise e classificação dos participantes - Atividade 5

Fonte: Acervo pessoal (2015) 
Nas atividades 4 e 5, buscamos trabalhar a percepção dos elementos da figura, como o uso da técnica do traçado do ponto de fuga em uma imagem em perspectiva, ou seja, o uso do "saber" geométrico para criar um elemento implícito na questão, relacionando-o com o que está representado, o polo do "visto".

$\mathrm{Na}$ figura da atividade 5, as representações das paralelas estavam menos aparentes, o que tornou necessária uma avaliação mais minuciosa da imagem. Assim como na atividade 4, a constância perceptiva e a codificação/decodificação eram de grande importância, pois havia elementos com menos características geométricas. Nenhum participante conseguiu, com precisão, determinar o ponto de fuga e a linha de horizonte; seis apresentaram soluções incompletas e quatro não utilizaram a técnica correta. Ficou evidente que a determinação das representações das paralelas em uma imagem nem sempre é algo simples, visto que o ambiente real da pintura não é conhecido e o paralelismo entre os segmentos é algo a ser deduzido.

Assim como no caso da Atividade 4, os participantes tiveram dificuldade de trazer, para o ambiente "real" de uma pintura, o conhecimento visto em um ambiente geométrico e o saber geométrico levou-os a reproduzir as projeções como uma projeção paralela. A resposta de A3 (Figura 20) mostra que ele conseguiu extrair a informação, mas cometeu alguns erros.

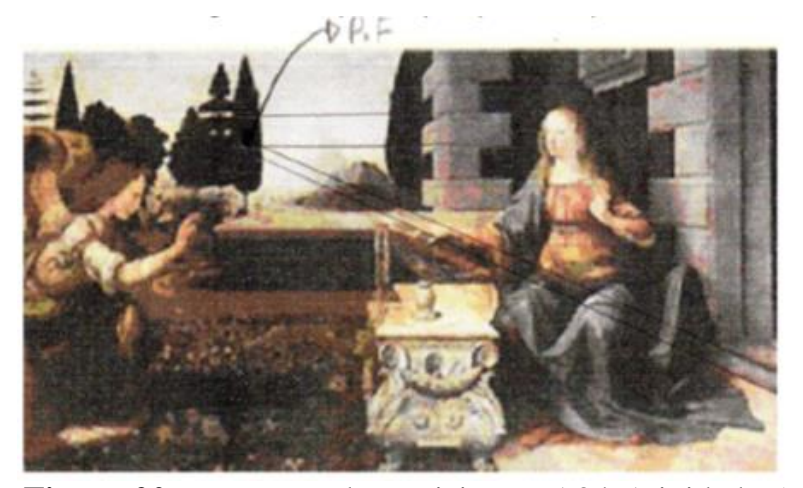

Figura 20 - Resposta do participante A3 à Atividade 5 Fonte: Acervo pessoal (2015).

Apresentamos, no terceiro encontro, construções com um software de Geometria Dinâmica 3D, nas quais representamos os planos de projeção e as projeções de elementos do plano horizontal (figuras planas e tridimensionais) destacando a localização de objetos reais e da imagem projetada, das linhas de terra e de horizonte e do observador. 

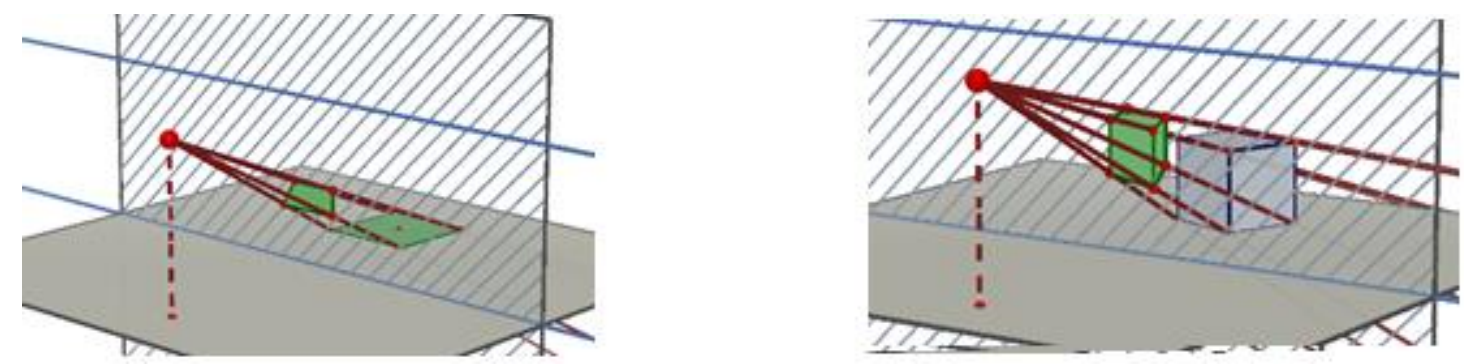

Figura 21- Projeção de um quadrado no plano vertical Figura 22 - Projeção de um cubo no plano vertical Fonte: Acervo pessoal (2015).

Mostramos inicialmente a projeção de um quadrado situado no plano real (Figura 21), cuja construção se dá pelas semirretas originadas do observador aos vértices do quadrado e que interceptam o plano de projeção, marcando os vértices da imagem projetada. Na Figura 22, apresentamos uma representação plana de uma figura tridimensional, pela projeção dos vértices das faces "visíveis" pelo observador de um cubo apoiado no plano real. Há algumas falhas nessa construção, pois, se girarmos o cubo, as faces não projetadas não aparecem e a "dinâmica", recurso importante do software, não atualiza a projeção e não temos uma representação correta do cubo rotacionado. Essa limitação do software não prejudica o entendimento, pois nos restringimos a ambientes tridimensionais estáticos, e não dinâmicos.

As construções das Figuras 23 e 24 serviram para mostrar o uso das técnicas nas imagens projetadas em perspectiva para recriar o ponto de fuga (ponto de encontro das representações em perspectiva de retas paralelas) e conhecer elementos do plano real que originaram uma pintura ou uma fotografia, sem conhecimento prévio do ambiente e introduzir algumas noções de geometria projetiva.
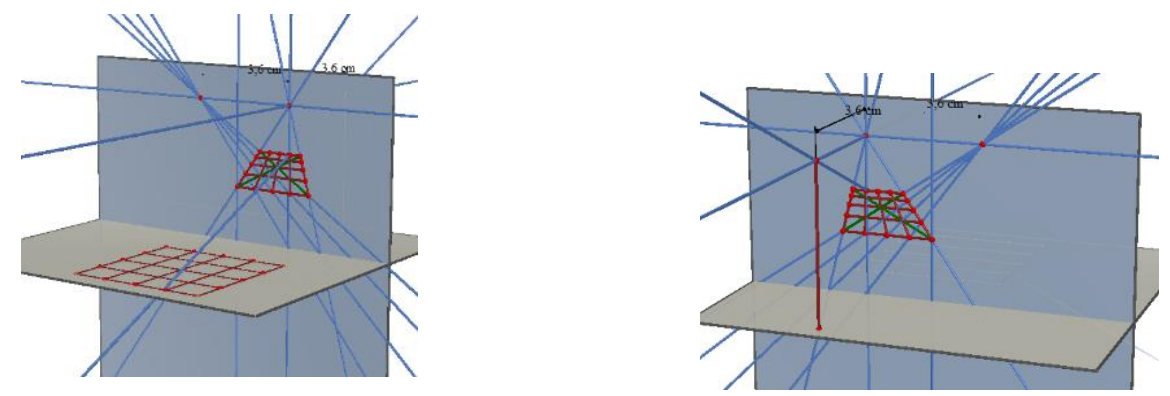

Figura 23 - Encontrando o Observador - Parte I Figura 24 - Encontrando o Observador - Parte II Fonte: Acervo pessoal (2015)

$\mathrm{Na}$ construção da Figura 24, utilizamos a projeção de uma malha quadriculada para estudar a construção de Alberti (1991) e verificar que a distância do observador à tela de pintura é igual à do ponto de fuga da malha ao ponto de fuga das diagonais, assim como Alberti (1991) propõe a construção para determinar os pontos por onde passam as paralelas ao 
plano de projeção.

Ao final deste encontro, que também foi o final da intervenção, os participantes responderam quatro perguntas sobre como um software de geometria dinâmica poderia tornar os assuntos mais interessantes e facilitar a compreensão dos modelos propostos.

O uso do software despertou um maior interesse no que se refere à geometria projetiva? Explique.

Procuramos usar o software para mostrar um jeito prático de apresentar conceitos que, em alguns casos, ficam restritos ao papel ou à lousa e interagir com o ambiente de projeção de um modo dinâmico, tornando mais viável a compreensão e o comportamento dos elementos. Por exemplo, na reconstrução de um objeto a partir de sua projeção, pudemos mostrar como a posição do observador altera a altura da linha de horizonte e a forma em que a projeção é representada, pois o ponto de vista está sendo deslocado.

Os participantes afirmaram que o uso do software despertou o interesse pelo assunto, não somente pela possibilidade de visualizar o que foi discutido nos encontros anteriores, mas também de trabalhar com essas ferramentas, no caso das reconstruções de imagens a partir de suas projeções. A resposta de A3 retrata o que buscávamos: "Sim. Dessa maneira se torna mais clara a visão de objetos tridimensionais e bidimensionais. Com tal aspecto desperta-me a atenção voltada a geometria projetiva! Conclui-se que há um mundo inimaginável voltado as formas geométricas" (Dados da pesquisa, 2015).

A relação entre os objetos dos planos de projeção, tais como planos horizontal e vertical, linhas de terra e de horizonte e observador, ficou mais clara com o uso do software? Explique.

O objetivo foi verificar se o uso do software permitiu maior facilidade para entender os elementos trabalhados nos planos de projeção, em comparação com as apresentações em lousa ou desenho. Buscamos unir os polos do "visto" e do "sabido" de Parzysz (1988) para verificar se, ao ver e entender os conceitos de uma figura representada em perspectiva, conseguiríamos uma possível superação das dificuldades conceituais vistas por Gutiérrez (1998).

Os resultados apontam que o bom uso do software auxilia os participantes a entenderem e diferenciarem os elementos de um ambiente tridimensional, sem haver confusão para representá-los. Por exemplo, A7 responde: "Sim, mas mostrando as figuras sem a projeção e apenas com a explicação já deixaria claro, a projeção ajudou mais" (Dados da 
pesquisa, 2015).

O objetivo da questão foi analisar se a compreensão das técnicas e propriedades apresentadas, na lousa ou em papel e lápis, foi facilitada pelo uso de um software de geometria dinâmica 3D. Procuramos criar uma relação mais direta entre os níveis de reprodução (PARZYSZ, 1988): a partir do Nível 0 (figura), passando para o Nível 1 (modelo, pela construção tridimensional do software) e seguindo para o Nível 2 (desenho, utilizando o processo de projeção apresentado pelo pesquisador).

Você considera que o uso de um software para a demonstração de conceitos na geometria pode ser um benefício no que se refere ao interesse e à compreensão do participante no assunto a ser ensinado?

Os participantes apontaram que ficou mais clara a representação de alguns elementos e porque as retas paralelas se encontram, quando projetadas. O participante A6 escreve: "Sim, porque como eu já disse esse software detalha muito e com esse detalhamento faz com que entenda melhor" (Dados da pesquisa, 2015).

Buscamos identificar se houve generalização dos conceitos estudados. Nas respostas, encontramos "fica mais interessante porque é uma aula diferente", "foge daquela coisa rotineira", "os participantes prestam mais atenção quando usam computador em sala" (Dados da pesquisa, 2015)., indicando que o uso do software traz benefícios, em termos de interesse e de compreensão.

Você considera que o uso do software colaborou para um melhor entendimento dos tópicos de geometria projetiva? Explique.

Das nove respostas favoráveis, trazemos duas que retratam o que buscávamos: "Sim, acredito que os alunos mostram mais interesse quando envolve aulas diferentes" e "Sim. Porque dessa maneira tira-se as dúvidas, pois com a 'visão' em si torna-se melhor para armazenar informações necessárias para a geometria” (Dados da pesquisa, 2015). Nesta segunda resposta, mesmo sem o conhecimento das ideias de Parzysz (1988), o participante mostra que compreende que "a visão", ou polo do "visto", tem direta influência no aprendizado e na assimilação de conhecimento.

\section{Conclusões}

Ficou evidente que o estudo histórico da perspectiva nas obras de arte pode ajudar a entender a importância dela nas pinturas e que o uso do software para entender e usar as 
técnicas em outras situações desperta o interesse pela Geometria. E mais, com isso atingimos um dos objetivos, que era o de apresentar outros tipos de Geometria, além da euclidiana, introduzindo elementos da Geometria projetiva por meio das ideias iniciais da perspectiva.

Pela comparação dos resultados de nossa pesquisa com as demais revisadas e com as ideias teóricas que usamos, pudemos fazer uma ligação entre os experimentos visuais de análise de imagens e a compreensão dos participantes. Assim como Souza (2010) e Bedim (2011), concluímos que a tríade professor, material, aluno é essencial para o entendimento das representações, pois o "sabido" do aluno pode não ser suficiente para a compreensão, seja das pinturas, seja das construções, como pudemos ver nas respostas dos participantes que não conseguiram concluir a atividade sem o auxílio do pesquisador.

Utilizamos modelos geométricos digitais para reproduzir as construções feitas com as máquinas de Dürer, permitindo aos participantes "testemunhar" o funcionamento e as características dessas máquinas. Assim, trabalhamos as mesmas ideias de Miranda (2006), Kodama (2006) e Meneguzzi (2009), que buscaram mostrar modos de representar, em um ambiente plano, figuras tridimensionais, ou com modelos de desenhos, ou com softwares ou com um aparato construído pelo pesquisador. Pudemos reconstruir os modelos que nos interessavam para explorar propriedades da perspectiva cônica e mostrar aos participantes como isso pode ser feito com papel e lápis ou com um software de Geometria dinâmica.

Mostramos como as projeções devem ser tratadas para que se assemelhem às construções reais e discutimos as diferenças entre as projeções estudadas. Fizemos assim uma ligação com os modelos de representação estudados por Gutiérrez (1998) e os polos do "visto" e do "sabido", definidos por Parzysz (1998). Pudemos reavaliar métodos estudados em outras pesquisas, como os procedimentos do perspectógrafo didático (MENEGUZZI, 2009) num software de Geometria dinâmica, de modo a possibilitar que alunos do Ensino Médio possam compreender a existência e a importância de outros tipos de geometria, utilizando a Geometria projetiva como porta de entrada. Buscamos ampliar o conhecimento dos participantes de modo a provocar um enriquecimento do saber e para que o "visto" tenha mais possibilidade de assimilação.

A primeira questão "O participante consegue perceber a importância da geometria projetiva para o trabalho com perspectiva nas obras de arte?” tem sua resposta na análise da primeira atividade, embora as perguntas feitas, em alguns casos, não tenham sido interpretadas geometricamente. Os participantes reconheceram a importância histórica da perspectiva nas obras de arte e como o surgimento das técnicas auxiliou a criação de pinturas 
que representam melhor as situações reais; contudo, as respostas não deixaram claro o entendimento do assunto, pois não souberam destacar os recursos que permitem determinar posicionamento e/ou tamanho dos elementos nas pinturas.

As atividades do segundo encontro deram elementos para respondermos a segunda questão de pesquisa "A utilização do software para trabalhar com projeções de figuras facilita o entendimento de tópicos da geometria projetiva?”, pois apresentamos aos participantes técnicas de representação de retas e de polígonos em um plano vertical de projeção para que, na terceira atividade, com o software, pudéssemos verificar se o uso do software facilita o entendimento de tópicos de geometria projetiva.

Essas atividades mostraram que, mesmo sem o software, os participantes assimilaram técnicas de projeção, sabendo usá-las em situações diferentes das apresentadas por nós. Contudo, em algumas situações, utilizaram saberes relacionados à geometria plana e buscaram, no próprio conhecimento - polo do "sabido" -, representar aquilo que queriam ver - polo do "visto". Nas duas atividades que envolveram a construção do ponto de fuga e da linha de horizonte, os participantes tentaram fazer um maior uso do "sabido", pois as retas que deveriam ser as paralelas da figura se assemelharam às retas paralelas na Geometria plana e, em alguns casos, não permitiram que o participante encontrasse o que era pedido na questão.

Quando apresentados às técnicas no software, no terceiro encontro, os participantes puderam ver de maneira mais clara como as representações funcionam e como as construções que fizeram seriam representadas em um ambiente tridimensional. Esse encontro foi fundamental para a pesquisa, pois mostrou que o uso do software despertou interesse pelo conteúdo e pelas representações. Ficou claro o que Parzysz (1988) fala sobre a perda de informação nas representações planas de figuras espaciais, pois, quando eliminamos essa perda, com o uso do software, aquilo que se vê ("visto") equipara-se ao que se conhece ("sabido") e há um ganho no entendimento, pois o software permite que se visualizem as duas representações e deixa de existir a dificuldade de ter que associar mentalmente os dois conceitos, "visto" e "sabido".

Ressaltamos que é necessária uma pesquisa mais aprofundada sobre a utilização de um software de Geometria dinâmica, com situações em que os participantes sejam parte atuante das construções. O uso pleno das ferramentas geométricas do software permite que se possa aplicar o que se conhece, sem depender de habilidades de desenho, e se melhore a capacidade de visualização. Acreditamos que situações desse tipo podem aumentar o interesse pela Geometria em alunos de qualquer nível de ensino. 


\section{Referências}

ALBERTI, Leon Battista. On Painting. Tradução Cecil Grayson. Reprint Edition. England: Penguin Classics, 1991. $112 \mathrm{p}$.

BEDIM, A. A. P. O ensino de conceitos geométricos no $2^{\circ}$ ano do Ensino Fundamental usando a Webquest "Viajando nas Obras de Arte". 2011. 172 f. Dissertação (Mestrado em Educação) Faculdade de Ciências e Tecnologia, UNESP, Presidente Prudente, 2011.

BRASIL. Ministério da Educação. Secretaria de Educação Média e Tecnológica. Parâmetros curriculares nacionais: ensino médio. Brasília, DF, 2015. Acessível em:

http://portal.mec.gov.br/seb/arquivos/pdf/CienciasNatureza.pdf. Acesso em: 23 abr. 2018.

BRASIL. Ministério da Educação. Secretaria de Ed. Básica. Base Nacional Comum Curricular. Disponível em:

http://portal.mec.gov.br/index.php?option=com_docman\&view=download\&alias=79601-anexo-textobncc-reexportado-pdf-2\&category_slug=dezembro-2017-pdf\&Itemid=30192>. Acesso em: 23 abr. 2018

COBB, P et al. Design Experiments in Educational Research. Educational Researcher, Washington DC, v. 32, n. 1, p. 9 - 13, jan/fev 2003.

GUTIÉRREZ, A. Las representaciones planas de cuerpos 3-dimensionales en la enseñanza de la geometría espacial. Revista EMA, Bogotá, v. 3, n. 3, p. 193 - 220, jul. 1998.

IMENES, L. M.; LELLIS, M. Matemática 9ª ano. São Paulo: Moderna, 2014.

KODAMA, Y. O estudo da perspectiva cavaleira: uma experiência no ensino médio. 2006. 192 p. Dissertação (Mestrado em Educação Matemática) - Faculdade de Ciências Exatas e Tecnológicas, Pontifícia Universidade Católica, São Paulo, 2006.

LELLIS, M. Desenho em perspectiva no ensino fundamental - considerações sobre uma experiência. In: Seminários De Ensino De Matemática, 2, 2009, São Paulo: Faculdade de Educação/USP, 2009. p.9.

MENEGUZZI, T. M. Os perspectógrafos de Dürer na educação matemática: história, geometria e visualização. 2009. 61 f. Dissertação (Mestrado em Educação Científica e Tecnológica) - Centro de Ciências da Educação, Universidade Federal de Santa Catarina, Florianópolis, 2009.

MIRANDA, S. S. de. O papel da Geometria Descritiva nos Problemas da Geometria Espacial: um estudo das secções de um cubo. 2006. 189 f. Dissertação (Mestrado em Educação Matemática) Faculdade de Ciências Exatas e Tecnológicas, Pontifícia Universidade Católica, São Paulo, 2006.

PARZYSZ, Bernard. "Knowing" vs "seeing". Problems of the plane representation of space geometry figures. Educational Studies in Mathematics, Netherlands, v.19, n. 1, p. 79 - 92, fev. 1988.

SOUZA, W. R. S. de. Representações planas de figuras tridimensionais: um estudo envolvendo visualização. 2010. 70f. Dissertação (Mestrado em Educação Matemática) - Pós-graduação em Educação Matemática, Universidade Bandeirante, São Paulo, 2010.

Submetido em 28 de Maio de 2018. Aprovado em 06 de Novembro de 2018. 